\title{
A PILOT STUDY ON THE QUALITY OF LIFE IN FAMILY CAREGIVERS OF CANCER PATIENTS AT AN URBAN TERTIARY HOSPITAL IN KUALA LUMPUR
}

\author{
Nik Nairan Abdullah',3), Idayu Badilla Idris'), Khadijah Shamsuddin'1), \\ Nik Muhd. Aslan Abdullah²) \\ 1)Department of Community Health, Universiti Kebangsaan Malaysia, Malaysia \\ 2)Department of Radiotherapy\&Oncology,Universiti Kebangsaan Malaysia, Malaysia \\ 3)Population Health \& Preventive Medicine, Universiti Teknologi MARA, Malaysia
}

\begin{abstract}
Background: Family plays an important role in caregiving of cancer patients. There are limited published articles on cancer caregiving in the Malaysian population. The aim of the study was to determine the quality of life (QoL) of cancer patient caregivers and its associated factors.

Subjects and Method: A cross-sectional study was conducted at an urban tertiary hospital in Kuala Lumpur, Malaysia. A total of 94 family caregivers of all types of cancer patients completed validated questionnaires in the national language. The dependent variable was theQoL in family caregivers, which was measured by the Malay Caregiver Quality of Life-Cancer (MCQOL-C) questionnaire. It consisted of 35 items, and the domains are burden, positive adaptation, disruptiveness, financial concerns and others. The higher the QoL scores, the better the QoL. The independent variables were socio-demographic factors (age, education level, ethnicity, gender, marital status, relationship with patient, any children less than 18 years old, and employment status). The data were analyzed by a linear regression model.

Results: The study population $(\mathrm{N}=94)$ comprised of $73.4 \%$ females, $38.8 \%$ were spouses to cancer patients. The mean age was $45.02 \pm 14.65$, ranged from 17-78 years old. Half $(56.4 \%)$ of the study subjects were Malays, $54.3 \%$ obtained secondary education, and 50\% were not working. The reliability of the questionnaire was good with Cronbach alpha $=0.87$. The mean (SD) score of QoL was 80.57 (21.27), ranged from 25-128. The multivariate analysis showed that being non-Malay had lower quality of life than Malay $(b=-18.40 ; 95 \% \mathrm{CI}=3.10$ to 33.70; $\mathrm{p}=0.020$ ).

Conclusion: Ethnicity affects the QoL of cancer patient caregiving. This provides invaluable insight for developing health care service.
\end{abstract}

Keywords: quality of life, family caregiver, cancer

\section{Correspondence:}

Nik Nairan Abdullah. Department of Community Health, Universiti Kebangsaan Malaysia, Kuala Lumpur, Malaysia. Email: niknairan@gmail.com.

Mobile: 60192655676. 